\title{
Influencia del sorbato potásico y del benzoato sódico sobre la estabilidad de las aceitunas de mesa en salmuera
}

\author{
Por V. Marsilio 1 y A. Cichelli 2 \\ 1. Istituto Sperimentale per la Elaiotecnica, Pescara, Italia \\ 2. Universita' G.D' Annunzio, Pescara, Italia
}

\section{RESUMEN}

Influencia del sorbato potásico y del benzoato sódico sobre la estabilidad de las aceitunas de mesa on salmuera

Se estudian los efectos del sorbato potásico y del benzoato sódico sobre las características físico-químicas, microbiológicas y organolépticas de conservas de aceitunas verdes de mesa.

Las aceitunas conservadas en frascos de vidrio a temperatura ambiente y en cámara termostática a $+28^{\circ} \mathrm{C}$, en condiciones aeróbicas para facilitar el crecimiento de levaduras y mohos superficiales, se tratan con fungistáticos en dos niveles de concentración calculados sobre la masa total de aceitunas y salmuera, respecto a los contenidos relativos.

Los resultados indican que los aditivos empleados son efectivos para la conservación del producto durante los dos primeros meses, sin que afecten al sabor de las aceitunas, mientras que se ha apreciado un cierto oscurecimiento en algunas muestras. Para aumentar el período anterior serian necesarias cantidades iniciales más altas, que den unos valores residuales del orden de los limites establecidos por el C.O.I.

PALABRAS-CLAVE: Aceituna verde de mesa - Aditivo (efecto de) Conservación.

\section{SUMMARY}

Effects of potassium sorbate and sodium benzoate on the stability of green table olives in brine

The results of a study on the effects of potassium sorbate and sodium benzoate on the chemical, microbiological and organoleptic characteristics of green table olives during the preservations, are presented.

The olives stored in glass vessels at room temperature and at $28^{\circ} \mathrm{C}$, in aerobic conditions, to promote the growth of surface yeasts and moulds, are added of fungistatics at two concentration levels, calculated by weight on the basis of the total content of the vessel; that is the weight of olives plus the weight of the water in the brine.

The results showed that these additives were effective to preserve the product a period of two months, without affecting the olive flavour. However a certain darkening of some samples was observed. To increase such period higher initial concentrations must be used, although their residual values should be within the limits permitted by the C.O.I.

KEY-WORDS: Additive (effect of) - Conservation - Green table olive.

\section{INTRODUCCION}

En un cuadro general de mejora de la industria conservera de aceitunas de mesa, resalta la necesidad de impedir, durante el almacenamiento y la comercialización del producto, el desarrollo de gérmenes que lo puedan alterar, en el primero de los casos, o reducir su vida de mercado, en el segundo.

Es frecuente, en efecto, que sobre la superficie de la salmuera de conservación de las aceitunas, se formen velos de tipo fúngico, blanquecinos, más o menos extensos, con aspecto liso o rugoso. La denominación anglosajona para estas formaciones es "film-yeasts", que hace alusión directamente al hecho de que están constituidas por levaduras. Asimismo, las mismas se asemejan a la conocida enfermedad de algunos vinos denominada "flor" (Verona, 1948).

Estos velos, debidos, pues, al desarrollo de levaduras oxidativas, constituyen un verdadero factor de inestabilidad del producto conservado, influyen negativamente sobre las características comerciales y representan un índice de que la salmuera está insuficientemente protegida pudiéndose desarrollar gérmenes entre los que se incluyen los responsables de putrefacciones.

Por otra parte, para la conservación de aceitunas de mesa, y en especial para las semifermentadas, la norma C.O.I. (C.O.I., 1980) a la cual se hace referencia generalmente en las transacciones comerciales a nivel internacional, autoriza el uso de los ácidos sórbico y benzoico y de sus sales como sustancias antimicrobianas.

Dicho procedimiento se contempla como alternativo a los costosos tratamientos términos, que, aunque eficaces, no están exentos de efectos negativos sobre la calidad organoléptica y nutricional del producto.

Pruebas de fermentación de pepinillos (Costilow et al., 1957; Etchells et al., 1960) han demostrado, que el ácido sórbico utilizado en concentraciones de 0,01 a $0,1 \%$ reduce, sin llegar a la inhibición completa, el desarrollo de las levaduras en la salmuera y no interfiere significativamente en la evolución de la flora acidificante. Los resultados han evidenciado que para obtener un efecto seguro en la salmuera es necesario aumentar las cantidades de aditivos a medida que el pH es más elevado y disminuye la concentración salina.

Experiencias de conservación de aceitunas de mesa (De la Borbolla et al., 1961; Savastano y Castorina, 1965) han evidenciado que la duración de la actividad fungistá- 
tica del ácido sórbico y de sus sales, está directamente relacionada con el porcentaje empleado del aditivo y que la flora bacteriana se afecta sólo ligeramente, al mismo tiempo que el color de la salmuera de las aceitunas tiende a sufrir un ligero oscurecimiento.

Por su parte, el ácido sórbico es utilizado en la conservación de alimentos en general por su acción antimicrobiana, que se explica a través de la inhibición de diferentes sistemas enzimáticos de los microorganismos respectivos, por su inocuidad fisiológica y su reducida influencia sobre las características organolépticas.

Por su baja constante de disociación puede ser usa- do en alimentos ácidos y poco ácidos, hasta un pH máximo de 6,5 (Tabla I) y actúa, principalmente, en forma de sal contra levaduras y mohos inhibiendo sólo parcialmente a las bacterias (Dziezak, 1986). Los resultados de las investigaciones sobre la actividad bacteriostática del ácido sórbico no siempre concuerdan (Scheneman y Costilow, 1955; Sofos, 1983; Sofos et al., 1979).

Es más, parece que en concentraciones ineficaces, algunos microorganismos, pueden metabolizarlo cuando se encuentran en una elevada densidad, produciendo $\mathrm{CO}_{2}$ y $\mathrm{H}_{2} \mathrm{O}$ (Luck, 1982; Deak y Novak, 1972; York y Vaughn, 1954).

Tabla I

Propiedades antimicrobianas de los ácidos sórbico y benzoico en los alimentos (Lindsay R.C., 1976)

\begin{tabular}{|c|c|c|c|c|c|}
\hline Aditivo & Fórmula & Forma activa* & $\begin{array}{l}\mathrm{pH} \text { de } \\
\text { actividad }\end{array}$ & $\begin{array}{l}\text { Mecanismo } \\
\text { de acción }\end{array}$ & $\begin{array}{l}\text { microorganismos } \\
\text { inactivados }\end{array}$ \\
\hline Acido sórbico & $\mathrm{CH}_{3}-\mathrm{CH}=\mathrm{CH}-\mathrm{CH}=\mathrm{CH}-\mathrm{COOH}$ & Acido no disociado & $\begin{array}{l}\text { La actividad es } \\
\text { inversamente } \\
\text { proporcional al pH, } \\
\text { hasta un valor límite } \\
\text { de } 6,5\end{array}$ & $\begin{array}{l}\text { Los mohos no } \\
\text { metabolizan los dobles } \\
\text { enlaces conjugados }\end{array}$ & $\begin{array}{l}\text { Mohos y } \\
\text { levaduras }\end{array}$ \\
\hline
\end{tabular}

Acido benzoico

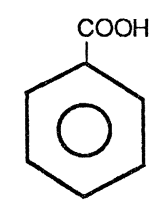

Los lactobacilos pueden reducir el ácido sórbico al alcohol correspondiente, el sorbitol, que reacciona con el etanol formando un éter que tiene un fuerte olor a geranio (Luck, 1982).

Este conservante es particularmente utilizado para los quesos, las frutas secas, productos de panadería, dulces, ensaladas especiales, bebidas, vegetales fermentados y encurtidos (King, 1981), utilizando concentraciones que oscilan del 0,01 al $0,1 \%$. Estos porcentajes se aumentan en un $25 \%$ si dicho aditivo se utiliza en forma de sales hidrosolubles (sorbatos). En la conservación de aceitunas de mesa, la proporción máxima permitida es de 0,5 $\mathrm{g} / \mathrm{kg}$ de producto, incluida la salmuera.

A su vez el ácido benzoico, comúnmente utilizado en forma de sal (benzoatos), es eficaz contra levaduras y bacterias, con actividad máxima en un rango de $\mathrm{pH}$ com- prendido entre 2,5 y 4,5 (Beuchat y Golden, 1989); por el contrario es menos eficiente en el control de mohos (Dziezak, 1986 Tabla I).

No obstante algunos autores sostienen que su actividad es principalmente contra mohos y levaduras más que frente a las bacterias (Chichester y Tanner, 1972).

Por su sabor dulce se aplica también como coadyuvante tecnológico, presentando la ventaja de ser inodoro e incoloro (Dziezak, 1986). El ácido benzoico se utiliza en los alimentos en una concentración máxima de $0,1 \%$ y ejerce su acción fungistática a través de la inhibición de determinados sistemas enzimáticos o la acidificación de las células microbianas (Beuchat y Golden, 1989). Bajo forma de sales el benzoato potásico es relativamente poco soluble, y se utiliza en cantidades que representan un incremento de alrededor de un $10 \%$, con respecto al 
benzoato sódico para obtener el mismo nivel de ácido benzoico en solución y la misma eficiencia antimicrobiana.

En las conservas de aceituna la concentración máxima permitida de ácido benzoico, según la norma C.O.I. es de $1 \mathrm{~g} / \mathrm{kg}$ de producto, incluida la salmuera.

En el presente trabajo se exponen los resultados de la investigación llevada a cabo con aceitunas verdes estilo sevillano para verificar la actividad fungistática del sorbato potásico y del benzoato sódico, así como su influencia sobre las características microbiológicas y organolépticas del producto durante su conservación hasta que se envasa. Durante este período, en efecto, se hace el desarrollo, más o menos extenso, de velos de levaduras y mohos en la superficie de contacto de la salmuera con el aire.

\section{MATERIALES Y METODOS}

Las pruebas se efectuaron con aceitunas verdes de la variedad "Intosso" y "Halkidiki", tratadas con lejía, suficientemente lavadas y semifermentadas.

Las experiencias se realizaron en frascos de vidrio conteniendo $1 \mathrm{~kg}$ de producto y $600 \mathrm{ml}$ de salmuera al $4 \%$; éstos frascos se guardaron en condiciones aeróbicas de conservación para facilitar el desarrollo de velos superficiales de levaduras.

Los frascos con las aceitunas se trataron en la forma siguiente:

- testigos (aceitunas sin aditivos);

- aceitunas tratadas con sorbato potásico en concentraciones de 0,13 y $0,25 \%(p / v)$ con respecto al volumen de salmuera; lo que representa $0,04 \mathrm{y}$ $0,07 \%$, expresadas como ácido sórbico y con relación al peso de aceitunas y salmuera;

- aceitunas tratadas con benzoato sódico en concentraciones de 0,26 y $0,50 \%(\mathrm{p} / \mathrm{v})$ sobre el volumen de salmuera, lo que significa 0,09 y $0,16 \%$ respectivamente expresado como ácido benzoico y en función también del peso conjunto.

Los porcentajes anteriores están calculados sobre la masa total de aceitunas y salmuera respecto a sus relativos contenidos en el frasco.

Por cada variedad y tratamiento se prepararon seis frascos, manteniendo tres de ellos a temperatura ambiente y los otros tres en estufa a $28^{\circ} \mathrm{C}$.

Periódicamente se efectuaron controles con objeto de detectar el desarrollo de velos de levaduras sobre la superficie de la salmuera.

Finalmente, al cabo de 6 meses de conservación se realizaron los controles químicos fundamentales $\mathrm{pH}$ y acidez total), microbiológicos y organolépticos.

Los análisis microbiológicos se realizaron en distintos medios de cultivo:

- carga microbiana total: Standard Plate Count Agar (Oxoid), incubada a $30^{\circ} \mathrm{C}$ durante 72 horas;
- levaduras: Malt Extract Agar (Oxoid), incubadas a $25^{\circ} \mathrm{C}$ durante 72 horas;

- mohos: Cooke Rose Bengal Agar (Difco) incubados a $25^{\circ} \mathrm{C}$ durante 72 horas;

- Clostridios sulfito-reductores en medio de cultivo sulfito sódico a pH 7,4 incubados a $37^{\circ} \mathrm{C}$ durante 48 horas.

Las siembras de las salmueras se hicieron por dilución para recuento, poniendo en la placa $1 \mathrm{ml}$ de diluciones previamente preparadas de dichas salmueras, y agitando suavemente con el medio correspondiente fundido y mantenido a $45^{\circ} \mathrm{C}$.

Para los Clostridios las siembras se realizaron siguiendo el método reportado por el Consejo Nacional de Investigaciones Científicas para análisis de las aguas (C.N.R., 1979).

En los frutos se determinaron la textura (deformación expresada en $\mathrm{mm} / \mathrm{g}$ de pulpa), según el método descrito en un trabajo anterior (Marsilio, 1983), y el color superficial con espectrofotómetro Beckman Du/70, provisto de accesorio de reflectancia y ordenador con programa específico para la medida de color y diferencias relativas expresadas como $\Delta E$ CIE.

Estas unidades de medidas están adaptadas por normas CIE para apreciar diferencias de color entre muestras de distintos productos. En la práctica diferencias de color hasta 1 se consideran apenas perceptibles por un observador medio, por el contrario valores mayores indican diferencias más evidentes y significativas. El método seguido para las medidas ha sido descrito en un trabajo anterior (Marsilio et al., 1990).

En los frutos se determinaron también el olor y el sabor con métodos sensoriales para evaluar la calidad correspondiente a cada tratamiento.

\section{RESULTADOS Y DISCUSION}

En la Tabla II se reúnen los resultados relativos a pH, acidez total (expresada en \% de ácido láctico) y textura junto a las características de olor y sabor de las muestras de aceitunas al cabo de seis meses de conservación. En conjunto los datos evidencian respecto a los niveles iniciales, una disminución de los valores de $\mathrm{pH}$, sin embargo no se encuentran diferencias evidentes entre los tratamientos.

Al mismo tiempo los valores de acidez total se sitúan alrededor del $0,50 \%$ en la variedad "Halkidiki" y $0,35 \%$ en la variedad "Intosso". Estos valores de acidez son correspondientes a los niveles característicos de las preparaciones de aceitunas verdes fermentadas y por tanto, de acuerdo con los datos encontrados en la bibliografía. Según ello, en las condiciones operativas adoptadas, los aditivos empleados no parecen influenciar la evolución de la población de lactobacilos. 
Tabla II

Características analíticas y organolépticas encontradas en conservas de aceitunas después de seis meses de conservación a temperatura ambiente $(A)$ y en termostato $a+28^{\circ} \mathrm{C}(T)$.

\begin{tabular}{|c|c|c|c|c|c|c|c|c|c|c|c|c|c|c|}
\hline \multirow[b]{3}{*}{ MUESTRA Y TRATAMIENTO } & \multicolumn{7}{|c|}{$\mathrm{HALK}|\mathrm{D}| \mathrm{K}$ I } & \multicolumn{7}{|c|}{ INTOSSO } \\
\hline & \multirow{2}{*}{$\begin{array}{c}N .{ }^{\mathrm{g}} \\
\text { frascos } \\
\text { positivos } \\
{ }^{*}\end{array}$} & \multicolumn{2}{|c|}{ Salmuera } & \multicolumn{2}{|c|}{ Textura } & \multicolumn{2}{|c|}{$\begin{array}{c}\text { Características } \\
\text { cualitativas } \\
\end{array}$} & \multirow{2}{*}{$\begin{array}{c}\mathrm{N} .{ }^{\circ} \\
\text { frascos } \\
\text { positivos } \\
.^{*}\end{array}$} & \multicolumn{2}{|c|}{ Salmuera } & \multicolumn{2}{|c|}{ Textura } & \multicolumn{2}{|c|}{$\begin{array}{c}\text { Características } \\
\text { cualitativas }\end{array}$} \\
\hline & & $\mathrm{pH}$ & $\begin{array}{l}\text { Acidez } \\
\text { (\% ac. } \\
\text { lactico) }\end{array}$ & $\begin{array}{c}\text { Deformación } \\
\text { en mm./g. } \\
\text { pulpa }\end{array}$ & $\begin{array}{l}\text { Desv. } \\
\text { Est. }\end{array}$ & Olor & Sabor & & $\mathrm{pH}$ & $\begin{array}{l}\text { Acidez } \\
\text { (\% ac. } \\
\text { lactico) }\end{array}$ & $\begin{array}{c}\text { Deformación } \\
\text { en mm./g. } \\
\text { pulpa " }\end{array}$ & $\begin{array}{l}\text { Desv. } \\
\text { Est. }\end{array}$ & Olor & Sabor \\
\hline Aceitunas originales & - & 5,10 & 0,21 & 0,55 & 0,05 & Bueno & Bueno & - & 4,90 & 0,33 & 0,58 & 0,06 & Bueno & Bueno \\
\hline Testigos & 2 & 4,29 & 0,54 & 0,60 & 0,09 & Caracteristico & Bueno & 2 & 4,47 & 0,40 & 0,56 & 0,07 & Caracteristico & Bueno \\
\hline Testigos & 1 & 4,30 & 0,54 & 0,53 & 0,09 & Caracteristico & Bueno & 1 & 4,72 & 0,39 & 0,62 & 0,12 & Caracteristico & Bueno \\
\hline Aceitunas con $0,05 \%$ Sorbato potásico $\mathrm{A}$ & 3 & 5,15 & 0,17 & 0,64 & 0,08 & Característico & Bueno & 1 & 4,86 & 0,24 & 0,62 & 0,07 & Característico & Mediocre \\
\hline Aceitunas con $0,05 \%$ Sorbato potásico $T$ & 0 & 5,08 & 0,23 & 0,60 & 0,09 & - & - & 2 & 4,52 & 0,40 & 0,65 & 0,12 & Caracteristico & Mediocre \\
\hline Aceitunas con $0,09 \%$ Sorbato potásico $\mathrm{A}$ & 3 & 4,31 & 0,54 & 0,64 & 0,08 & Caracteristico & Bueno & 3 & 4,78 & 0,31 & 0,57 & 0,07 & Característico & Bueno \\
\hline Aceitunas con $0,09 \%$ Sorbato potásico $T$ & 3 & 4,11 & 0,58 & 0,54 & 0,05 & Característico & Bueno & 3 & 4,64 & 0,35 & 0,66 & 0,10 & Caracteristico & Bueno \\
\hline Aceitunas con $0,10 \%$ Benzoato sódico $A$ & 2 & 4,25 & 0,54 & 0,63 & 0,09 & Caracteristico & Mediocre & 0 & - & - & - & - & - & - \\
\hline Aceitunas con $0,10 \%$ Benzoato sódico $\mathrm{T}$ & 3 & 4,25 & 0,52 & 0,57 & 0,06 & Caracteristico & Bueno & 3 & 4,53 & 0,40 & 0,69 & 0,07 & Caracteristico & Bueno \\
\hline Aceitunas con $0,19 \%$ Benzoato sódico A & 3 & 4,29 & 0,50 & 0,58 & 0,09 & Característico & Bueno & 0 & - & - & - & - & - & - \\
\hline Aceitunas con $0,19 \%$ Benzoato sódico $T$ & 3 & 4,32 & 0,42 & 0,51 & 0,05 & Característico & Bueno & 3 & 4,56 & 0,40 & 0,74 & 0,07 & Caracteristico & Bueno \\
\hline
\end{tabular}

(`) Frascos que no presentan velos en la superficie de sus salmueras.

(*) Valores medios de diez determinaciones cada muestra. 
Tabla III

Composición de la población microbiana (valores individuales) encontrada después de seis meses de conservación, ambiente (A) y termostato (T), en algunas muestras de salmueras de aceitunas de los diferentes sistemas de tratamiento (log UFC/ml).

\begin{tabular}{|c|c|c|c|c|c|c|c|c|c|c|c|c|c|c|c|c|c|c|c|c|c|c|}
\hline \multirow{5}{*}{ ANALISIS } & \multicolumn{11}{|c|}{$H A L K|D| K \mid$} & \multicolumn{11}{|c|}{ INTOSSO } \\
\hline & \multirow{4}{*}{ 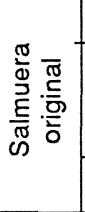 } & \multicolumn{10}{|c|}{ Salmuera después de la conservación } & \multirow{4}{*}{ 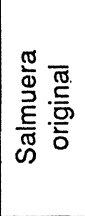 } & \multicolumn{10}{|c|}{ Salmuera después de la conservación } \\
\hline & & \multirow{2}{*}{\multicolumn{2}{|c|}{$\begin{array}{l}\text { Salmuera } \\
\text { testigo }\end{array}$}} & \multicolumn{4}{|c|}{ con Sorbato potásico } & \multicolumn{4}{|c|}{ con Benzoato sódico } & & \multirow{2}{*}{\multicolumn{2}{|c|}{$\begin{array}{c}\text { Salmuera } \\
\text { testigo }\end{array}$}} & \multicolumn{4}{|c|}{ con Sorbato potásico } & \multicolumn{4}{|c|}{ con Benzoato sódico } \\
\hline & & & & \multicolumn{2}{|c|}{$0,05 \%$} & \multicolumn{2}{|c|}{$0,09 \%$} & \multicolumn{2}{|c|}{$0,10 \%$} & \multicolumn{2}{|c|}{$0,19 \%$} & & & & \multicolumn{2}{|c|}{$0,05 \%$} & \multicolumn{2}{|c|}{$0,09 \%$} & \multicolumn{2}{|c|}{$0,10 \%$} & \multicolumn{2}{|c|}{$0,19 \%$} \\
\hline & & A & $\mathrm{T}$ & A & $T$ & A & $T$ & A & $\mathrm{T}$ & A & $\mathrm{T}$ & & A & $\mathrm{T}$ & A & $\mathrm{T}$ & A & $\mathrm{T}$ & A & $\mathrm{T}$ & A & $\mathrm{T}$ \\
\hline Recuento microbiano tot. & 6,39 & 5,34 & 5,25 & 5,53 & 9,32 & 5,00 & 4,60 & 7,28 & 4,96 & 4,48 & 4,35 & 6,40 & 6,20 & 6,25 & 7,18 & 5,15 & 5,07 & 4,93 & 9,18 & 4,78 & 9,79 & 4,60 \\
\hline Levaduras & 3,84 & 3,50 & 3,77 & 3,47 & 5,82 & 5,25 & 1,50 & 4,70 & 1,81 & 1,40 & 0,90 & 5,18 & 4,48 & 4,60 & 7,13 & 2,45 & 1,65 & 1,30 & 5,20 & 0,90 & 6,46 & 0,60 \\
\hline Mohos & 2,39 & 2,77 & 2,70 & 1,93 & - & - & - & 4,00 & - & - & - & 4,20 & 3,30 & 3,40 & 1,70 & - & - & - & 5,65 & - & 4,58 & - \\
\hline Lactobacilos & 3,80 & 5,17 & 5,15 & 3,48 & - & 5,20 & 5,30 & - & 4,89 & 4,54 & 4,50 & 4,15 & 4,57 & 4,30 & - & 4,20 & 4,00 & 4,18 & - & 4,25 & - & 4,10 \\
\hline Clostridios S-R & - & - & - & - & 0,50 & - & - & 1,36 & - & - & - & - & - & - & 0,50 & - & - & - & 1,45 & - & 0,60 & - \\
\hline
\end{tabular}


Tabla IV

Caracteristicas del color relativas a la luminosidad y pureza de las aceitunas después de seis meses de conservación a temperatura ambiente (A) y en termostato (T).

\begin{tabular}{|c|c|c|c|c|c|c|c|c|c|c|c|c|c|c|}
\hline \multirow{3}{*}{ MUESTRA Y TRATAMIENTO } & \multicolumn{7}{|c|}{$H A L K|D| K \mid$} & \multicolumn{7}{|c|}{ I NTOSSO } \\
\hline & \multirow{2}{*}{$\mathrm{x}$} & \multirow{2}{*}{$\mathrm{Y}$} & \multicolumn{2}{|c|}{ Luminosidad * } & \multicolumn{2}{|c|}{ Pureza * } & \multirow{2}{*}{$\lambda d$} & \multirow{2}{*}{$x$} & \multirow{2}{*}{$\mathrm{Y}$} & \multicolumn{2}{|c|}{ Luminosidad * } & \multicolumn{2}{|c|}{ Pureza * } & \multirow{2}{*}{$\lambda d$} \\
\hline & & & $\%$ & Desv. Est. & $\%$ & Desv. Est. & & & & $\%$ & Desv. Est. & $\%$ & Desv. Est. & \\
\hline Aceitunas originales & 0,349 & 0,362 & 17,6 & 1,71 & 21,8 & 4,73 & 572 & 0,347 & 0,360 & 16,5 & 1,41 & 20,9 & 3,45 & 571 \\
\hline Testigos & 0,374 & 0,372 & 21,6 & 1,42 & 31,2 & 3,30 & 576 & 0,353 & 0,353 & 17,8 & 0,49 & 20,9 & 1,28 & 576 \\
\hline Testigos & 0,372 & 0,368 & 21,7 & 1,56 & 29,6 & 2,66 & 577 & 0,356 & 0,354 & 17,7 & 0,80 & 21,2 & 1,95 & 577 \\
\hline Aceitunas con $0,05 \%$ Sorbato potásico $A$ & 0,362 & 0,361 & 18,6 & 0,64 & 25,4 & 1,81 & 576 & 0,358 & 0,360 & 18,2 & 1,04 & 23,8 & 1,71 & 576 \\
\hline Aceitunas con $0,05 \%$ Sorbato potásico $\mathrm{T}$ & 0,369 & 0,365 & 20,8 & 0,95 & 28,3 & 1,66 & 577 & 0,362 & 0,361 & 18,5 & 0,86 & 25,3 & 1,77 & 576 \\
\hline Aceitunas con $0,09 \%$ Sorbato potásico $\mathrm{A}$ & 0,368 & 0,368 & 21,3 & 1,63 & 28,9 & 3,00 & 576 & 0,356 & 0,359 & 19,6 & 0,87 & 23,0 & 1,71 & 576 \\
\hline Aceitunas con $0,09 \%$ Sorbato potásico $T$ & 0,370 & 0,367 & 21,0 & 0,88 & 29,0 & 1,89 & 576 & 0,360 & 0,360 & 19,7 & 0,75 & 24,2 & 1,17 & 576 \\
\hline Aceitunas con $0,10 \%$ Benzoato sódico $\mathrm{A}$ & 0,370 & 0,369 & 21,3 & 0,69 & 29,4 & 1,87 & 576 & 0,346 & 0,347 & 14,6 & 2,06 & 16,7 & 5,75 & 577 \\
\hline Aceitunas con $0,10 \%$ Benzoato sódico $\mathrm{T}$ & 0,368 & 0,365 & 21,0 & 0,85 & 28,0 & 1,81 & 576 & N.D. & N.D. & N.D. & N.D. & N.D. & N.D. & N.D. \\
\hline Aceitunas con $0,19 \%$ Benzoato sódico $\mathrm{A}$ & 0,367 & 0,365 & 20,4 & 1,24 & 27,6 & 2,87 & 576 & N.D. & N.D. & N.D. & N.D. & N.D. & N.D. & N.D. \\
\hline Aceitunas con $0,19 \%$ Benzoato sódico $\mathrm{T}$ & 0,372 & 0,369 & 21,3 & 1,06 & 30,1 & 2,00 & 577 & 0,349 & 0,346 & 15,6 & 0,70 & 17,7 & 1,71 & 578 \\
\hline
\end{tabular}

(") Valores medios de veinte determinaciones cada muestra. 
La textura de los frutos se mantiene aceptable, no obstante la disminución observada en el curso de la conservación, en ambas variedades. Del análisis de varianza realizado a partir de los resultados individuales se desprende que no hay diferencias significativas entre los distintos tratamientos.

El olor y el sabor de las conservas no alteradas fueron característicos del tipo de producto, no revelando gustos particulares ligados a la presencia de los aditivos.

Los controles periódicos efectuados durante la conservación pusieron de relieve la presencia de velos, más o menos extensos sobre la superficie de las salmueras testigos al primer mes.

Al mismo tiempo y a los dos meses, las salmueras tratadas no presentaron desarrollo de velos, después algunos de los tratamientos que contenían fungistáticos en las concentraciones más bajas, manifestaron señales de proliferación fúngica con desarrollo de micelio abundante en algunas muestras. Los análisis de tales muestras revelaron ablandamiento de los frutos, olores desagradables, una relevante carga bacteriana y presencia de esporas de Clostridios sulfito-reductores.

Los resultados de los análisis microbiológicos de muestras de salmueras, algunas de las cuales alteradas por la presencia de Clostridios, de ambas las variedades, recogidos en la Tabla III, demuestran, en efecto, que el empleo de fungistáticos en concentraciones ineficaces, por debajo de los límites establecidos por la norma C.O.I., no ha tenido un efecto protector satisfactorio. Así en dichas muestras se encontraron valores elevados de la carga bacteriana total con densidades celulares del orden de $10^{6}$ colonias $/ \mathrm{ml}$, de levaduras en densidades superiores a $10^{5}$ colonias $/ \mathrm{ml}$ y de microorganismos esporulados de Clostridios sulfito-reductores en un número inferior a 30 .

Por el contrario en las salmueras tratadas con concentraciones más elevadas de fungistáticos el desarrollo de levaduras fue muy reducido y los mohos prácticamente se inhibieron. En general, los datos indican que la composición microbiológica de las conservas de aceitunas fue influenciada sensiblemente por la concentración del aditivo y en particular por la cantidad residual en el producto. En efecto, los análisis realizados sobre el producto al finalizar las pruebas de conservación, han revelado la presencia de una cantidad residual de 0,0025\% de ácido sórbico, que representa sólo el $6 \%$ aproximadamente, de la proporción inicial, y de 0,03-0,09\% de ácido benzoico, correspondientes respectivamente al 33 y al $56 \%$ de las concentraciones utilizadas al inicio de la experiencia.

Las cantidades de ácido sórbico fueron, pues, notablemente reducidas respecto a la concentración máxima permitida de $0,5 \%$ y por lo tanto, considerando la inestabilidad del aditivo, debido a la actividad metabólica de los microorganismos, se hubieran requerido concentraciones sensiblemente mayores para asegurar en el producto elaborado una presencia cuantitativamente más significativa, y así haber conferido a la salmuera condiciones más satisfactorias de conservabilidad. Sin embargo, el empleo de concentraciones más elevadas podría afectar a las características organolépticas del producto.
El ácido benzoico empleado en la concentración de $0,16 \%$, fue hallado en cantidades del $0,09 \%$, cantidad que se encuentra dentro de los límites fijados por la norma C.O.I. $(0,1 \%)$.

Los resultados de los análisis colorimétricos (Tabla IV) indican un aumento de los valores de pureza y luminosidad en la variedad "Halkidiki" pasando respectivamente del 22 y $18 \%$ del producto inicial al 31 y $22 \%$ en los testigos conservados; en la variedad "Intosso" los mismos parámetros quedan sustancialmente invariables con un leve aumento de la luminosidad que pasa del 17 al $18 \%$.
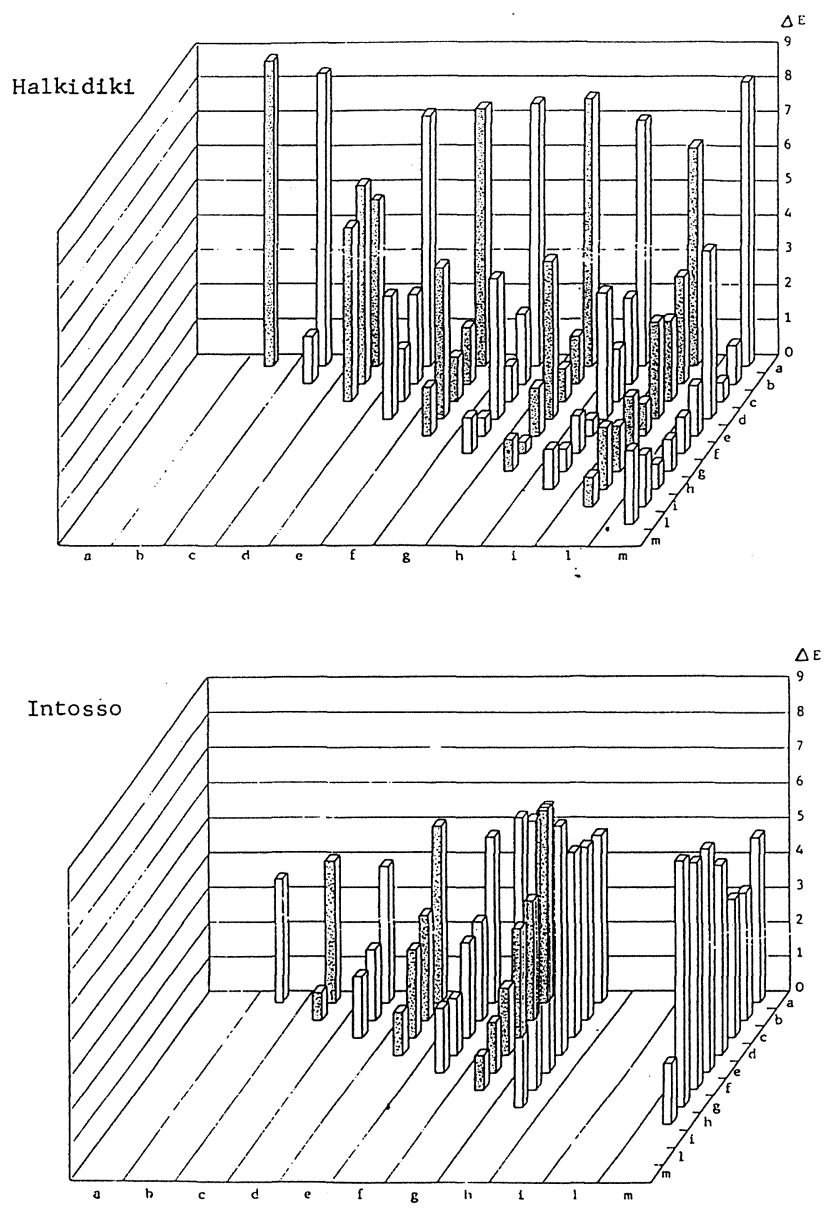

Figura 1

Diferencias de color $(\Delta E)$ encontradas entre las muestras de las aceitunas de las variedades Halkidiki y Intosso al finalizar el tiempo de la conservación.

(Un observador medio puede apreciar diferencias mayores de l'unidade).

$a=$ producto original; $b=$ testigos $A ; c=$ testigos $T$;

d, e = tratamiento con $0,05 \%$ de Sorbato potásico A e T;

$\mathrm{f}, \mathrm{g}=$ tratamiento con $0,09 \%$ de Sorbato potásico $\mathrm{A}$ e T;

$h, \mathrm{i}=$ tratamiento con $0,10 \%$ de Benzoato sódico $\mathrm{A}$ e $\mathrm{T}$;

I, $m=$ tratamiento con $0,19 \%$ de Benzoato sódico A e T. 
Las muestras tratadas presentan, respecto a los testigos, un leve aumento de los valores de pureza y luminosidad en la variedad "Intosso", con exclusión de las tratadas con benzoato sódico que sufren, por el contrario, una disminución, así como en todos los tratamientos de la variedad "Halkidiki".

No obstante del estudio estadístico de los datos individuales se pone de manifiesto que, con respecto a estos parámetros, no se encuentran diferencias significativas entre los tratamientos en la variedad "Halkidiki", mientras en el "Intosso" las diferencias son significativas solamente para las muestras tratadas con benzoato.

Las disminuciones de dichos parámetros denota la aparición de un leve fenómeno de oscurecimiento, más evidente en las aceitunas de la variedad "Intosso", tratadas con benzoato. Sobre las modificaciones de las características cromáticas de las muestras testigos, puede haber influido el $\mathrm{pH}$; sin embargo, entre los distintos tratamientos la influencia del $\mathrm{pH}$ es menos evidente y parece, de acuerdo con los datos de la bibliografía, que el leve oscurecimiento de algunas muestras de aceitunas podría ser debido, en parte, a la presencia de los conservantes.

Las modificaciones observadas encuentran su confirmación en los valores $\Delta \mathrm{E}$ (diferencias de color) (Figura 1) que aumentan con la conservación, mientras las diferencias de color que se hallan entre las muestras tratadas, no muestran una tendencia clara y apenas son perceptibles.

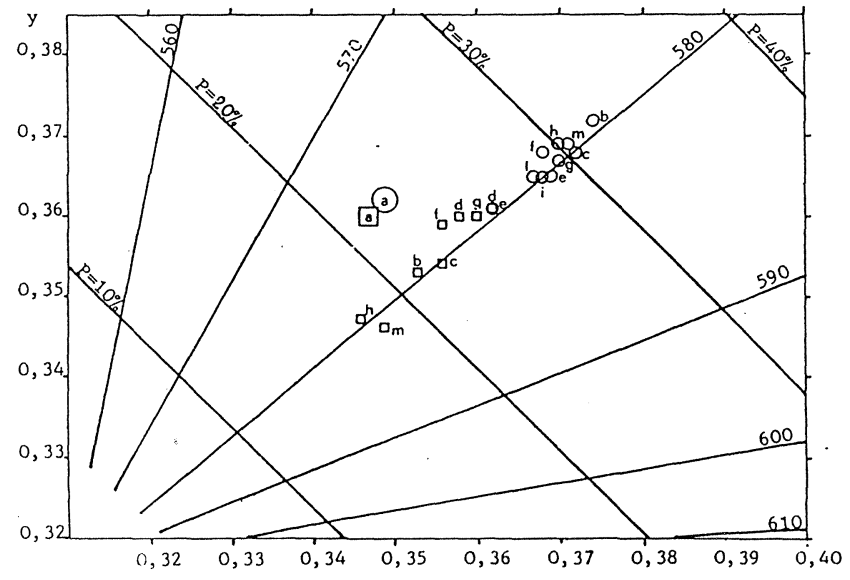

Figura 2

Representación de la zona de color ocupada por las muestras de aceitunas de las vairedades Halkidiki (o) y Intosso ( $(0)$ sobre el diagrama de cromaticidad C.I.E. (las letras indican el punto de color relativo al producto inicial (a), testigos $(b-c)$ y tratados $(d-m))$.
En la Figura 2 se puede apreciar la representación del color de las aceitunas sobre el diagrama de cromaticidad C.I.E.. La misma permite evidenciar las características cromáticas en términos de longitud de onda dominante, parámetro de preciso significado físico. Las muestras examinadas ocupan la zona de color comprendida entre 572 y $580 \mathrm{~nm}$ de longitud de onda dominante y entre el 18 y el $32 \%$ de pureza. La zona de color ocupada por el producto original es diferente de aquella ocupada por los testigos mientras las muestras tratadas ocupan una zona de color intermedia. En la variedad "Intosso" además se nota una mayor variabilidad de las características de color encontradas.

\section{CONCLUSIONES}

En el presente trabajo los resultados obtenidos permiten hacer las siguientes consideraciones:

- el empleo de sorbato potásico y de benzoato sódico en la conservación de las aceitunas verdes de mesa reduce, de acuerdo con los datos de la literatura, el desarrollo de las levaduras y de mohos en la salmuera mejorando así la vida de mercado de la conserva.

- La acidez producida en las salmueras no está influenciada significativamente por la presencia de los fungistáticos.

- Los aditivos empleados son verdaderamente efectivos para la conservación del producto durante los primeros dos meses. Para mayores períodos se necesitan concentraciones que aseguren en el producto estabilizado cantidades residuales correspondientes a los límites fijados por la norma C.O.I.. El empleo de concentraciones más elevadas de fungistáticos, sin embargo, podría afectar a las características organolépticas de las conservas.

- En las condiciones operativas adoptadas, los aditivos empleados no afectan al sabor de las aceitunas, mientras que con relación al color se aprecia, en algunas muestras, la aparición de un leve fenómeno de oscurecimiento subjetivamente apenas perceptible.

\section{AGRADECIMIENTO}

Los autores desean expresar su agradecimiento a $\mathrm{M}$. De Angelis por su colaboración.

\section{BIBLIOGRAFIA}

1. Beuchat, L.R. and Golden, D.A. (1989).- "Antimicrobials occurring naturally in foods".- Food Technol. January.

2. Chichester D.F. and Tanner, F.W. (1972).- 'Antimicrobial food additives".- Handbook of food additives, 2 ed. Ed. T.E. Furia. 115. Chem. Rubber PU.Co, Cleveland, Ohio.

3. C.N.R. (1979).- "Metodi analitici per le acque".- Vol. III, Istituto di Ricerche sulle acque, Multigrafica Editrice, Roma.

4. C.O.I. (1980).- "Norma qualitativa unificata applicabile alle olive da tavola nel commercio internazionale".- Madrid. 
5. Costilow, R.N.; Coughlin, F.M.; Robbins E.K. and Wen-Tau, HSU. (1957).- "Sorbic acid as a selective agent in cucumber fermentations. Effect of sorbic acid on the yeast and lactic acid fermentations in brined cucumbers".- Appl. Microbiol. 5.

6. Deak, T. and Novak, E.K. (1972).- "Assimilation of sorbic acid by yeasts".- Acta Alimentaria 1, 87.

7. De la Borbolla, J.M.R. y Alcalá; Fernández Diez, M.J.; González Gancho, F. (1961).- "Empleo del ácido sórbico, o sus sales en las aceitunas aderezadas'.- Grasas y Aceites 12.

8. Dziezak, J.D. (1986).- "Special report systems in food-preservatives: antimicrobial agent, a means toward product stability".- Food Technol., September.

9. Etchells, J.L.; Borg, A.F. and Bell, T.A. (1960).- "Influence of sorbic acid on populations and species yeasts occurring in cucumber fermentations".- Appl. Microbiol, 9.

10. King, B.B. (1981).- "Microbial inibition in bakery products, a review".Bakers digest, October.

11. Lindsay, R.C. (1976).- Other desiderable constituents of food Ch.10. In "Principles of food Science, part. 1: Food Chemistry". O.R. Fennema (Ed.), p. 465, Marcel Dekker Inc. New York N.Y.

12. Luck, E. (1982).- "Conservazione chimica degli alimenti: ieri, oggi, domani".- La Rivista della Societa Italiana di Scienza dell'Alimentazione, Anno II, 2.

13. Marsilio, V. (1983).- "Durometro sperimentale per la valutazione della consistenza della polpa delle olive da tavola". - Atti IV Congreso Internazionale di Merceologia - Bari 26/29 Settembre.

14. Marsilio V.; Brighigna A. e Cichelli, A. (1990).- "Le caratteristiche del colore delle olive nere da travola. Influenza della varieta e della tecnologia'.- Industrie Alimentari XXIX, Gennaio.

15. Savastano, G. e Castorina, S. (1965).- "La conservazione delle olive verdi da tavola. L'azione fungistatica dell'acido sorbico nelle salamoie".- L'ttalia Agricola n. 11, Novembre.

16. Scheneman, J.M. and Costilow, R.N. (1955) - "Sorbic acid as a preservative for swueet cucumber pickles".- Appl. Microbiol, 3, 186.

17. Sofos, J.N. (1983).- "Antimicrobial effects of sodium and other ions in foods, a review". - J. Food Safety 6, 45

18. Sofos, J.N.; Busta, F.F. and Allen C.F. (1979).- "Botulism control by nitrite and sorbate in cured meats, a review".- J. Food Protection 42, 9.

19. Verona, O. (1948).- "I lieviti delle olive in salamoia".- Olearia, Luglio.

20. York, G.K. and Vaughn, R.H. (1954).- "Use of sorbic acid enrichment media for species of Clostridium".- J. Bacteriol. 68, 739.

(Recibido: Junio 1991) 